\title{
Pra Desain Integrasi Mini LNG Plant di Gresik dan Regasifikasi Storage Unit di Smelter Banjarmasin
}

\author{
Lettizia Kris Harjanto, M.D. Citta Nirmala Wibowo, Gede Wibawa, dan Rizky Tertrisyanda \\ Departemen Teknik Kimia, Fakultas Teknologi Industri, Institut Teknologi Sepuluh Nopember (ITS) \\ e-mail: gwibawa@chem-eng.its.ac.id
}

\begin{abstract}
Abstrak-Dalam penelitian ini telah dilakukan perancangan pabrik Integrasi Mini LNG Plant dan Regasifikasi Storage Unit dengan kapasitas produksi LNG 20 MMSCFD (140.000 ton/tahun), waktu operasi 24 jam dan 330 hari/tahun. Tujuan perancangan Integrasi Mini LNG Plant dan Regasifikasi Storage Unit adalah untuk memenuhi kebutuhan LNG di Smelter Banjarmasin sebesar 15 MMSCFD (105.000 ton/tahun). Mini LNG Plant ini direncanakan akan didirikan di Kota Gresik, Provinsi Jawa Timur. Alasan pemilihan tempat ini adalah karena letaknya yang dekat dengan sumber bahan baku, yaitu dibeli dari Pertamina Hulu Energi (PHE) yang didapatkan dari sumur Poleng, lepas pantai Pulau Madura bagian utara. LNG ini nantinya diharapkan dapat memenuhi kebutuhan di Smelter Banjarmasin, Kalimantan Selatan. Proses pembuatan LNG dari gas alam pabrik ini menggunakan proses on-shore LNG dengan rangkaian proses berturut-turut sebagai berikut: penghilangan $\mathrm{CO}_{2}$ dan $\mathrm{H}_{2} \mathrm{~S}$ menggunakan amine absorbtion dengan solvent MDEA, penghilangan kandungan air dengan molecular sieve, refrigerasi dan pencairan gas alam menggunakan Single Mixed Refrigerant dengan bahan Mixed Component Refrigerant. Sedangkan untuk regasifikasi proses yang terjadi adalah menggunakan Open Rack Vaporizers. Dari rangkaian proses ini menghasilkan produk LNG kapasitas 18,29 MMSCFD (128.000 ton/tahun) dengan kadar HHV 1061 BTU/scf, LPG Mix 1,094 MMSCFD (8.000 ton/tahun), condensate 0,2229 MMSCFD (2.000 ton/tahun) Pendirian pabrik ini menggunakan dana investasi yang berasal dari modal sendiri sebesar $20 \%$ biaya investasi dan modal pinjaman sebesar $80 \%$ biaya investasi dengan bunga $12 \%$. Dari analisa perhitungan ekonomi, didapatkan hasil investasi sebesar 81.667.000 US\$ dengan IRR investasi sebesar 33,83\%, POT selama 4 tahun 2 bulan, dan NPV 12 tahun sebesar 59.990.000 US\$
\end{abstract}

Kata Kunci-Mini LNG plant, Regasifikasi Storage Unit, Gresik, Smelter Banjarmasin.

\section{PENDAHULUAN}

$\mathrm{G}$ AS alam atau biasa disebut dengan gas bumi adalah bahan bakar yang terbentuk dari fosil. Sebagian besar komonen gas alam terdiri dari metana $\left(\mathrm{CH}_{4}\right)$ dan sisanya adalah gas hidrokarbon yang lain seperti etana, propana,butana, pentana, juga gas-gas yang mengandung sulfur dan bahan-bahan yang lain. Biasanya ditemukaan di ladang minyak, ladang gas bumi, dan tambang batu bara. Karakteristik gas alam pada keadaan murni antara lain tidak berwarna, tidak berbentuk, dan tidak berbau. Selain itu, gas alam mampu menghasilkan pembakaran yang bersih dan hampir tidak menghasilkan emisi buangan yang dapat merusak lingkungan.

Selain itu, gas alam yang dimiliki Indonesia juga merupakan salah satu kekayaan alam yang cukup banyak.
Menurut data ESDM 2013, Indonesia memiliki cadangan gas bumi yang besar dengan nilai gas bumi yang telah terbuktikan sebesar 101,54 TSCF, potensial sebesar 48,85 TSCF, dan total 150,39 TSCF. Kondisi ini menunjukan bahwa gas alam yang dimiliki oleh Indonesia berpotensi tinggi untuk dikelola lebih lagi untuk memenuhi kebutuhan energi. Karena manfaat dan keunggulan dari gas alam menyebabkan gas alam banyak diminati di dunia industri sebagai bahan bakar. Salah satu solusi untuk mengatasi permintaan dan pasokan gas adalah dengan menyalurkan gas alam sebagai LNG (Liquefied Natural Gas).

Liquefied Natural Gas (LNG) adalah produk pengolahan gas alam yang dicairkan dengan cara didinginkan pada temperatur sekitar $-160^{\circ} \mathrm{C}$ dan pada tekanan atmosfer. Proses tersebut juga berfungsi untuk menghilangkan ketidakmurnian dan hidrokarbon berat pada gas alam. Dengan pencairan gas alam, volume spesifik gas akan mengecil hingga 1/600 kali lipat dibandingkan dengan kondisi awalnya.

Namun, seiring dengan peningkatan kebutuhan gas alam pada kenyataanya masih ada permasalahan distribusi yang kurang merata di berbagai daerah. Untuk menyelesaikan masalah ini, beberapa perusahaan mulai membuat saluran pipa-pipa gas dan kendaraan truk pengangkut LNG. Namun untuk menyuplai gas alam pada daerah jarak jauh dan melewati laut, penggunaan sistem transportasi menggunakan pipa dan truk pengangkut menjadi terkendala karena kurang efektif dan membutuhkan biaya yang lebih besar..Pemanfaatan gas alam sebagai bahan bakar dapat menghemat biaya kapital, menaikkan efisiensi bahan bakar.

Pendirian plant LNG dengan kapasitas kecil yang biasa disebut dengan Mini LNG plant, dapat menjadi salah satu solusi untuk memberikan supply LNG dengan jumlah yang sesuai dengan kebutuhan.Pada dasarnya, teknologi yang digunakan pada mini LNG plant merupakan penggabungan dari teknologi pencairan, transportasi, penyimpanan dan regasifikasi LNG. Dengan kapasitas antara 3 hingga 30 MMSCFD ( sekitar 2.000 hingga 500.000 ton/tahun), Mini LNG plant merupakan pilihan yang potensial untuk mengangkut gas alam ke daerah penerima yang terpencil, ketika mode transportasi lainnya dinilai tidak ekonomis untuk kondisi geografis wilayah Indonesia di luar Jawa dan Sumatera. Jaringan pembangunan pipa di Indonesia bagian tengah maupun timur tidak cocok dibangun, untuk itu diperlukan terminal pengangkutan dan penerima Mini LNG yang merupakan solusi yang strategis untuk menyeimbangkan kesenjangan antara pasokan dan permintaan sehubungan dengan kondisi geografis dan jarak antara pasokan gas dengan titik-titik penerimaan di daerah. 
Salah satu permasalahan pasokan LNG yang dapat diselesaikan dengan pendirian pabrik ini adalah pemenuhan kebutuhan LNG sebagai bahan bakar pembangkit listrik pada industry Smelter Banjarmasin, Kalimantan Utara yang membutuhkan pasokan LNG sebesar 15 MMSCFD (105.000 ton/tahun).

\section{URAIAN PROSES}

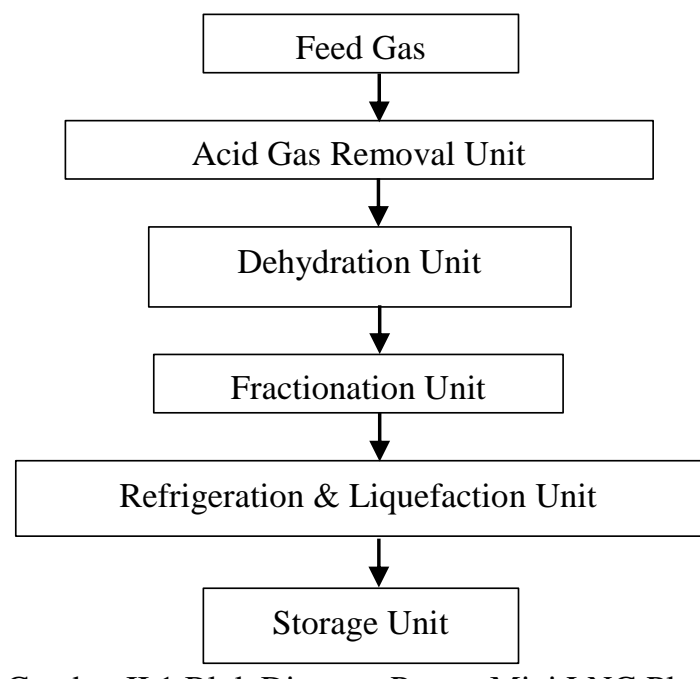

Gambar II.1 Blok Diagram Proses Mini LNG Plant

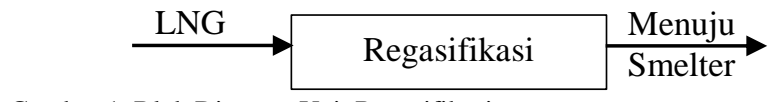

Gambar 1. Blok Diagram Unit Regasifikasi

Pada pembuatan LNG terdapat beberapa proses. Proses yang terjadi yaitu persiapan bahan baku pada Acid Gas Removal Unit serta Dehydration Unit, kemudian proses pembentukan produk yaitu pada Fractionation Unit serta Refrigeration \& Liquefaction Unit, dan proses sebelum penyaluran produk yaitu pada Regasification Unit. Bahan baku berasal dari Pertamina Hulu Energi (PHE) yang didapatkan dari sumur Poleng, lepas pantai Pulau Madura bagian utara, yang langsung dialirkan menuju LNG Plant di Gresik menggunakan pipa. Komposisi feed gas yang digunakan dalam perencaan Mini LNG Plant dan Regasifikasi Storage Unit ini tertera pada Tabel 1.

Tabel 1.

Komposisi Feed

\begin{tabular}{cc}
\multicolumn{2}{c}{ Komposisi Feed } \\
\hline \hline Komponen & \% mol \\
\hline Methane & 84.4565 \\
Ethane & 6.1016 \\
Propane & 4.3218 \\
i-Butane & 1.0526 \\
n-Butane & 1.2761 \\
i-Pentane & 0.4421 \\
n-Pentane & 0.3151 \\
Hexane $(+)$ & 0.3662 \\
$\mathrm{CO}_{2}$ & 0.6092 \\
$\mathrm{~N}_{2}$ & 1.0588 \\
\hline \hline
\end{tabular}

\section{A. Acid Gas Removal Unit}

Proses pertama yaitu persiapan bahan baku, dimana feed gas dialirkan langsung menuju Acid Gas Removal Unit. Pada Acid Gas Removal Unit, dilakukan pengabsorbsian $\mathrm{CO}_{2}$ dari feed gas hingga kadarnya maksimum 50 ppmV dengan tujuan untuk mencegah terjadinya pembekuan $\mathrm{CO}_{2}$ pada saat pencairan (liquefaction). Proses ini juga dapat menyerap $\mathrm{H}_{2} \mathrm{~S}$ yang terdapat dalam feed gas hingga batas maksimum 4 ppm.
Proses absorbs ini berlangsung pada temperature standard $( \pm$ $30-45^{\circ} \mathrm{C}$ ) dan tekanan yang tinggi, sedangkan untuk proses regenerasi amine pada temperature tinggi $\left( \pm 80^{\circ} \mathrm{C}\right)$ dan tekanan rendah. Feed gas masuk ke Absorber Column dari bagian bawah absorber dan akan kontak dengan lean amine yang masuk melalui bagian atas kolom dan mengalir turun ke bawah melalui tray-tray berupa sieve tray. Kemudian, di traytray inilah terjadi proses absorbsi $\mathrm{CO}_{2}$ dan $\mathrm{H}_{2} \mathrm{~S}$. Setelah meninggalkan absorber, feed gas akan didinginkan dengan melewatkannya pada Sweet Gas Air Cooler yang menggunakan media pendingin berupa udara hingga mencapai suhu $\pm 35^{\circ} \mathrm{C}$ dengan maksud agar jika masih ada moisture maupun MDEA yang terikut dalam feed gas dapat terkondensasi. Setelah itu, feed gas akan dialirkan ke Sweet Gas Flash Drum untuk memisahkannya dengan cairan yang terkondensasi. Feed gas yang keluar dari bagian atas Sweet Gas Flash Drum dikirim ke Dehydration Unit, sedangkan cairan yang berada pada bagian bottom Sweet Gas Flash Drum akan dialirkan ke aliran regenerasi rich amine.

Proses regenerasi amine dilakukan menggunakan kondisi operasi pada tekanan rendah dan temperature yang cukup tinggi sehingga $\mathrm{CO}_{2}$ dalam rich amine dapat terpisah. Sebelum masuk pada Amine Regeneration Column, rich amine dipanaskan dengan dengan media panas berupa lean amine yang berasal dari bottom kolom regenerasi hingga mencapai suhu $80^{\circ} \mathrm{C}$. Rich amine tersebut kemudian masuk ke dalam kolom dan terjadi proses pemisahan $\mathrm{CO}_{2}$ dari rich amine. Gas $\mathrm{CO}_{2}, \mathrm{H}_{2} \mathrm{~S}$ dan uap air yang berupa gas akan keluar dari puncak kolom regenerasi dan masuk ke Air Cooler untuk didinginkan suhunya sebelum dilepas ke atmosfer, sedangkan lean amine digunakan kembali untuk menyerap $\mathrm{CO}_{2}$ di kolom absorber. Air dan MDEA yang dikeluarkan dari puncak kolom regenerasi ini bertujuan untuk membantu mendinginkan temperature puncak kolom sehingga uap air yang keluar dari puncak kolom dapat dikurangi karena berkontak dengan cairan refluks, sedangkan campuran gas yang tidak dapat terkondensasi dibuang ke atmosfer. Sebelum digunakan kembali, lean amine yang berasal dari bottom kolom regenerasi diambil panasnya untuk memanasi rich amine dan kemudian dinaikkan tekanannya menggunakan Lean Amine Pump serta didinginkan menggunakan air pada Lean Amine Air Cooler.

\section{B. Dehydration Unit}

Proses selanjutnya yaitu penghilangan kandungan air yang terdapat dalam feed gas pada Dehydration Unit. Proses ini diperlukan dikarenakan air yang diperbolehkan terkandung dalam feed gas untuk diolah menjadi LNG yaitu kurang dari 1 ppm. Feed gas yang telah diserap $\mathrm{CO}_{2}$ dan $\mathrm{H}_{2} \mathrm{~S}$-nya (Sweet Gas) pertama-tama dinaikkan tekanannya menjadi 35 bar dengan menggunakan Feed Dehydration Compressor sebelum masuk ke dalam unit Molecular Sieve type 3A. Feed kemudian dialirkan ke dalam Molecular Sieve dari bagian atas kolom dehidrasi dan gas yang sudah bebas dari $\mathrm{H}_{2} \mathrm{O}$ keluar dari bagian bawah kolom. Tujuan dari aliran feed dari atas kolom adalah agar memperbesar waktu kontak antara feed gas dengan Molecular Sieve, sehingga proses adsorbsi akan berjalan maksimal. Dari molecular sieve, akan dihasilkan gas alam sebagai produk atas dengan suhu $70^{\circ} \mathrm{C}$ dan liquid sebagai produk bawah berupa air dengan suhu $50^{\circ} \mathrm{C}$. 


\section{Fractionation Unit}

Gas yang berasal dari Dehydration Unit didinginkan terlebih dahulu menggunakan coolbox LNG Exchanger sampai suhu $-53^{\circ} \mathrm{C}$. Selanjutnya akan dialirkan ke dalam PreCooled LNG Flash Drum untuk dipisahkan fase gas dan liquidnya sehingga fase gas akan bercampur dengan fase gas dari Deethanizer Column dan dilewatkan ke coolbox LNG Exchanger untuk diliquifaksi, sedangkan fase liquidnya dimasukkan ke Deethanizer Column. Deethanizer Column berfungsi untuk memisahkan metana dan etana dari fraksi berat lainnya pada tekanan 30 bar. Aliran yang keluar dari atas kolom didinginkan oleh LNG Separator Overhead Cooler yang mengakibatkan ada sebagian gas akan terkondensasi. Gas yang terkondensasi akan dipisahkan dalam $L N G$ Separator Overhead Accumulator dan akan dipompakan kembali sebagai reflux. Sedangkan metana dan etana yang tidak terkondensasi akan didinginkan dan dicairkan dengan menggunakan coolbox LNG Exchanger dengan kandungan gas metana minimal $85 \%$ mol.

Produk bawah Deethanizer Column akan keluar dari bagian bawah kolom dan dipanaskan pada reboiler. Produk bawah yang menjadi uap dikembalikan kedalam kolom dan produk bawah yang masih berfase liquid dialirkan menuju Debuthanizer Column dengan suhu $109.0{ }^{\circ} \mathrm{C}$. Kolom ini merupakan kolom fraksinasi yang digunakan untuk memisahkan propane dan butana dari hidrokarbon berat lainnya. Produk atas kolom ini mengandung butane dan propana, karena titik didih propane lebih kecil dari pada butane, sehingga saat butane menguap maka sebelumnya propana juga menguap. Gas propane dan butana yang keluar dari bagian atas kolom akan didinginkan dalam LPG Separator Overhead Cooler sampai suhunya $99.45^{\circ} \mathrm{C}$. Karena fase propana dan butana setelah keluar dari $L P G$ Separator Overhead Cooler masih berupa vapor maka akan didinginkan kembali dengan Air Cooler sampai suhunya $40^{\circ} \mathrm{C}$ dan sudah berfase liquid. Produk bawah Kolom Pemisah LPG berupa liquid yang disebut kondensat yang merupakan fraksi berat akan dipanaskan dalam Reboiler. Produk kondensat akan bersuhu $195^{\circ} \mathrm{C}$ dan sudah berfase liquid.

\section{Refrigeration \& Liquefaction Unit}

Sistem refrigerasi yang digunakan dalam proses pembuatan LNG ini yaitu sistem Single Mixed Refrigerant dengan refrigerant berupa Mixed Component Refrigerant yang terdiri dari campuran metana, etana, propana, dan nitrogen. Unit ini berfungsi untuk mendinginkan aliran gas alam dan mencairkan gas alam menjadi LNG.

Gas yang akan masuk $L N G$ Separator didinginkan terlebih dahulu dalam coolbox LNG Exchanger dengan menggunakan MCR. Kemudian MCR yang telah menyerap panas akan masuk ke dalam First Stage MCR Compressor untuk dinaikkan tekanannya menjadi 4 bar. Kemudian gas tersebut akan didinginkan di dalam MCR Intercooler Heat Exchanger sampai $35^{\circ} \mathrm{C}$. Kemudian MCR akan dinaikkan kembali tekanannya dengan menggunakan Second Stage Compressor menjadi 16.10 bar, lalu didinginkan kembali dengan menggunakan MCR Cooler. Setelah itu, MCR akan dinaikkan kembali tekanannya dengan menggunakan Third Stage MCR Compressor menjadi 64 bar dan kemudian didinginkan dengan menggunakan MCR Aftercooler Heat Exchanger. Setelah itu, MCR yang telah melalu tahap kompresi akan masuk kedalam coolbox LNG Exchanger untuk tahap pendinginan oleh MCR itu sendiri. Kemudian, MCR yang keluar dari coolbox LNG exchanger akan diekspansikan dengan MCR Expansion Valve sehingga tekanannya 0.5 bar dan $-165.6{ }^{\circ} \mathrm{C}$. MCR yang telah dingin ini siap untuk mendinginkan aliran yang akan menuju Fractionation Unit, mencairkan LNG yang keluar dari atas kolom LNG separator menjadi produk LNG, serta untuk mendinginkan MCR itu sendiri. Sehingga MCR yang telah keluar dari coolbox akan berubah fasenya menjadi uap dan akan masuk ke dalam $M C R$ Compressor.

LNG yang telah menjadi liquid keluar dari coolbox pada suhu $-151.8^{\circ} \mathrm{C}$ dengan tekanan 28.90 bar. Aliran ini kemudian diturunkan tekanannya menjadi 2 bar dengan Expansion Valve dengan suhu $-153.8^{\circ} \mathrm{C}$. Aliran ini kemudian dimasukkan ke dalam LNG Flash Tank untuk dipisahkan fase gas dan liquidnya, sehingga fase gasnya akan menjadi bahan bakar (fuel gas) dan fase liquid dikirim ke LNG Storage Tank.

\section{E. Regasification Unit}

Unit regasifikasi ini merupakan unit untuk mengubah LNG menjadi gas alam kembali sehingga dapat digunakan dan disalurkan langsung ke konsumen. Plant ini berada di tempat tujuan dekat power plant yang berada di Smelter Banjarmasin. Proses regasifikasi LNG ini dilakukan di terminal daratan dengan menggunakan media pemanas berupa steam.

LNG pada suhu $-153.8^{\circ} \mathrm{C}$ dari storage tank dialirkan masuk menuju LNG Pump untuk dinaikkan tekanannya menjadi 36 bar (high pressure jet pump) sesuai dengan tekanan yang dibutuhkan untuk LNG yang memasuki smelter. Aliran ini kemudian menuju ke Open Rack Vaporizers. Vaporizers ini menggunakan steam sebagai pemanas, dimana pada alat tersebut terjadi pertukaran panas antara LNG yang bersuhu $-160^{\circ} \mathrm{C}$ dengan steam yang kemudian menghasilkan gas alam dengan suhu $30^{\circ} \mathrm{C}$ dengan tekanan 36 bar. Pada storage tank, terdapat boi- off gas yang memiliki suhu $-153.8^{\circ} \mathrm{C}$ dan tekanan 1 bar yang kemudian masuk ke $L N G$ Vapor Compressor untuk dinaikkan tekanannya menjadi 36 bar. Keluaran kompresor ini memiliki suhu $72.6^{\circ} \mathrm{C}$ sehingga kemudian dilewatkan pada Heat Exchanger untuk menurunkan suhunya menjadi $30^{\circ} \mathrm{C}$. LNG boil-off gas yang keluar dari HE ini kemudian digabungkan dengan aliran LNG yang berasal dari Open Rack Vaporizers dan langsung dialirkan menuju Smelter Banjarmasin menggunakan pipa, dengan suhu $29.13^{\circ} \mathrm{C}$ dan tekanan 36 bar.

\section{MATERIAL BALANCE}

Berdasarkan hasil perhitungan material balance pada pabrik integrasi Mini LNG plant dan regasifikasi storage unit membutuhkan bahan baku awal berupa gas alam sebanyak 153.000 ton/tahun, MDEA sebnayak 1,17 ton/tahun, dan molecular sieve sebanyak 0,3151 ton/tahun yang menghasilkan LNG sebanyak 128.000 ton/tahun dengan spesifikasi HHV sebesar $1061 \mathrm{BTU} / \mathrm{scf}$, kandungan metana $91 \%$, butana $0,1 \%$, kandungan $\mathrm{CO}_{2}$ sebesar 1 ppmV, dan kandungan $\mathrm{H}_{2} \mathrm{~S}$ sebesar 1 ppmV. Selain itu, juga dihasilkan LPG mix sebanyak 8.000 ton/tahun dengan spesifikasi kandungan campuran propane dan butana sebesar $98 \%$, serta condensate sebanyak 2.000 ton/tahun dengan spesifikasi reid vapour pressure sebesar 1,2 psig. 


\section{ANALISA EKONOMI}

Dari hasil perhitungan neraca ekonomi, didapatkan Total Cost Investment untuk pabrik ini sebesar Rp 1.093.115.731.297, Internal Rate of Return (IRR) sebesar 33,83\%, Net Present Value (NPV) 12 tahun sebesar 59.990.000 US\$, dan waktu pengembalian modal (Pay Out Time) selama 4 tahun 2 bulan. Pabrik beroperasi secara kontinyu selama 330 hari dan 24 jam.

\section{KESIMPULAN}

Hasil analisa perhitungan pada Pra Desain Integrasi Mini LNG Plant dan Regasifikasi Storage Unit diperoleh beberapa kesimpulan antara lain :

- Dari segi teknis :

- Kapasitas produksi yang mampu dihasilkan sebesar 128.000 ton LNG/tahun serta 8.000 ton LPG/tahun.

- Lokasi pendirian pabrik adalah Kota Gresik, Jawa Timur dengan target distribusi Smelter Banjarmasin, Kalimantan Selatan.

- Bentuk hukum perusahaan yang direncanakan adalah Perseroan Terbatas (PT).

- Bentuk organisasi yang direncanakan adalah organisasi sistem garis dan staf dengan jumlah tenaga kerja yang dibutuhkan sebanyak 205 orang.

Dari segi ekonomis :

- Modal investasi $\quad: 81.667 .000$ US\$

- Biaya produksi per tahun : 76.100 .000 US\$

- Hasil jual produk per tahun : 101.030.000 US\$

- Laba bersih per tahun : 24.920 .000 US\$

- Internal Rate of Return : :33,83\%

- Pay Out Time : 4 tahun 2 bulan

- Net Present Value 12 tahun : 59.990.000 US\$

Dari hasil analisa baik aspek teknis dan ekonomis dapat disimpulkan bahwa pabrik Integrasi Mini LNG Plant dan Regasifikasi Storage Unit ini layak untuk didirikan.

\section{DAFTAR PUSTAKA}

[1] Brownell, Lloyd E. and Edwin H. Young. 1979. Process Equipment Design. New Delhi : Wiley Eastern Limited
[2] Caswell, Chris. 2014. Liquefied Natural Gas (LNG). SPE Roughneck Camp.

[3] Gas Processors Suppliers Association. 2004. Engineering Data Book FPS Version Volume I \& II. Oklahoma: Gas Processors Suppliers Association.

[4] Geankoplis, Christie J. 1983. Transport Process and Separation Process Principles $2^{\text {nd }}$ Edition. Massachusetts: Allyn and Bacon, Inc.

[5] Habibullah, Arif, Peter Lardi, dan Matthew Passmore. 2009. LNG Conceptual Design Strategies. San Antonio: 88th GPA Annual Convention.

[6] Himmelblau, David M. 1996. Basic Principles and Calculation in Chemical Engineering. New Jersey : Prentice Hall International Inc.

[7] International Gas Union. 2015. Small Scale LNG. Paris: World Gas Conference.

[8] Kern, Donald Q. 1965. Process Heat Transfer. Singapore: McGrawHill Book Company, Inc.

[9] Kirk and Othmer. 1967. Encyclopedia of Chemical Technology. New York: John Wiley and Sons.

[10] Kunert, Sebastian dan Oystein Bruno Larsen. 2010. Small is Beautiful - Mini LNG Concept. Norway: Hamworthy Gas Systems AS.

[11] Levenspiel, Octave. 1999. Chemical Reaction Engineering (3rd Edition). New York: John Wiley and Sons, Inc.

[12] Ludwig, Ernest E. 1997. Applied Process Design for Chemical and Petrochemical Plants Volume 2 Third Edition. Houston: Gulf Publishing Company.

[13] McCabe.W.L. and Smith.J.C. 1985. Operasi Teknik Kimia. Jakarta: Erlangga.

[14] Moon, J.W., Y.P. Lee, Y.W. Jin, E.S. Hong dan H.M. Chang. 2007. Cryogenic Refrigeration Cycle for Re-Liquefaction of LNG Boil-Off Gas. Colorado: International Cryocooler Conference, Inc.

[15] Nuswantara, Muhammad Rum Pandu, Wiryawan Priharmanto dan Gede Wibawa. 2014. Regasification of LNG (Liquefied Natural Gas). JURNAL TEKNIK POMITS. Vol. 3:2

[16] Perry, Robert H. 1999. Perry's Chemical Engineers' Handbook (7th Edition). New York: McGraw-Hill Book Company, Inc.

[17] Peters, Max S. dan Klaus D. Timmerhaus. 1958. Plant Design and Economics for Chemical Engineers 4th Edition. Singapore: McGrawHill Book Co.

[18] Smith, JM, H.C. Van Ness dan M.M. Abbot. 1987. Introduction to Chemical Engineering Thermodynamics (4th Edition). New York: McGraw-Hill Book Company, Inc.

[19] Ulrich, Gael D. 1984. A Guide to Chemical Engineering Process Design and Economics. New York: John Wiley and Son, Inc.

[20] Wisnu, Monica, Fatika Ellena, Winarsih dan Gede Wibawa. 2013 Studi Awal Desain Pabrik Mini LNG dari Gas Alam dengan Kapasitas Feed 20 MMSCFD. JURNAL TEKNIK POMITS. Vol 2:1.

[21] Winata, Adi Indra. 2008. Perancangan Shell and Tube Heat Exchanger Tipe Fixed Head dengan Menggunakan Desain 3D Template. Jakarta: Universitas Indonesia. 